\title{
Current situation of lung transplantation in Japan
}

\author{
Chihiro Konoeda, Masaaki Sato \\ Department of Thoracic Surgery, The University of Tokyo Hospital, Tokyo, Japan \\ Contributions: (I) Conception and design: Both authors; (II) Administrative support: None; (III) Provision of study materials or patients: Both authors; \\ (IV) Collection and assembly of data: Both authors; (V) Data analysis and interpretation: Both authors; (VI) Manuscript writing: Both authors; (VII) \\ Final approval of manuscript: Both authors. \\ Correspondence to: Masaaki Sato, MD, PhD. Department of Thoracic Surgery, The University of Tokyo Hospital, 7-3-1 Hongo, Bunkyo-ku, Tokyo \\ 113-8655, Japan. Email: satom-sur@h.u-tokyo.ac.jp.
}

\begin{abstract}
The first lung transplantation (LTx) from a neurologically dead donor (NDD) was performed in 2000 in Japan. This was 2 years after the first LTx from living donors. A total of 250 patients underwent bilateral and 276 patients underwent unilateral LTx procedures from NDDs from then to 2019. The number of LTx s has been increasing since revision of the Japanese organ transplantation law in 2010. However, the shortage of donors and the long waiting time (>2 years) remain problematic. Donation after cardiac death is impractical because controlled death is not permitted in Japan. We challenge the donor shortage with the use of a medical consultant system in which medical consultants give suggestions to the intensivists who care for possible donors, aggressive use of marginal donors such as older donors, smokers, suicidal hanging donors, donors who have contralateral pneumonia, and donors with a long intubation time, preoperative extracorporeal membrane oxygenation support, and living-donor LTx. In total, 234 cases of living-donor LTx were performed. Despite the aggressive use of marginal donors, outcomes in Japan are comparable with international outcomes. Careful assessment of marginal donors and meticulous management of possible donors are important key factors in rescuing as many patients as possible in the currently difficult situation of LTx in Japan.
\end{abstract}

Keywords: Living-related lung transplantation (LTx); lobar lung transplantation; donor shortage; waiting time; waiting list

Received: 20 August 2020; Accepted: 25 January 2021; Published: 25 February 2022.

doi: $10.21037 /$ ccts-20-143

View this article at: http://dx.doi.org/10.21037/ccts-20-143

\section{Introduction}

The first successful lung transplantation (LTx) was performed in 1983 in Toronto, Canada. The first LTx in Japan, which was a living-donor LTx, was performed in 1998. The first LTx from a neurologically dead donor (NDD) in Japan was successfully performed in 2000. The number of organ donations has been gradually increasing; however, the shortage of NDDs remains problematic. Donation after cardiac death is impractical because controlled death is not permitted in Japan. In this article, we describe the current status of LTx in Japan and how we challenge the shortage of NDDs.

\section{History}

In 1997, the Japanese organ transplantation law was issued in Japan. This law allowed organ donation from NDDs or brain-dead donors. In the first version of this law, confirmation of the written will of the possible donor was required at the time of donation. Families were unable to donate organs without the donor's written will. Therefore, the number of NDDs remained small.

In 2010, the law was amended. Organ donation became legal with only the family's will, even in the absence of the donor's written will. This revision largely affected the number of available NDDs and thus the number of LTx 


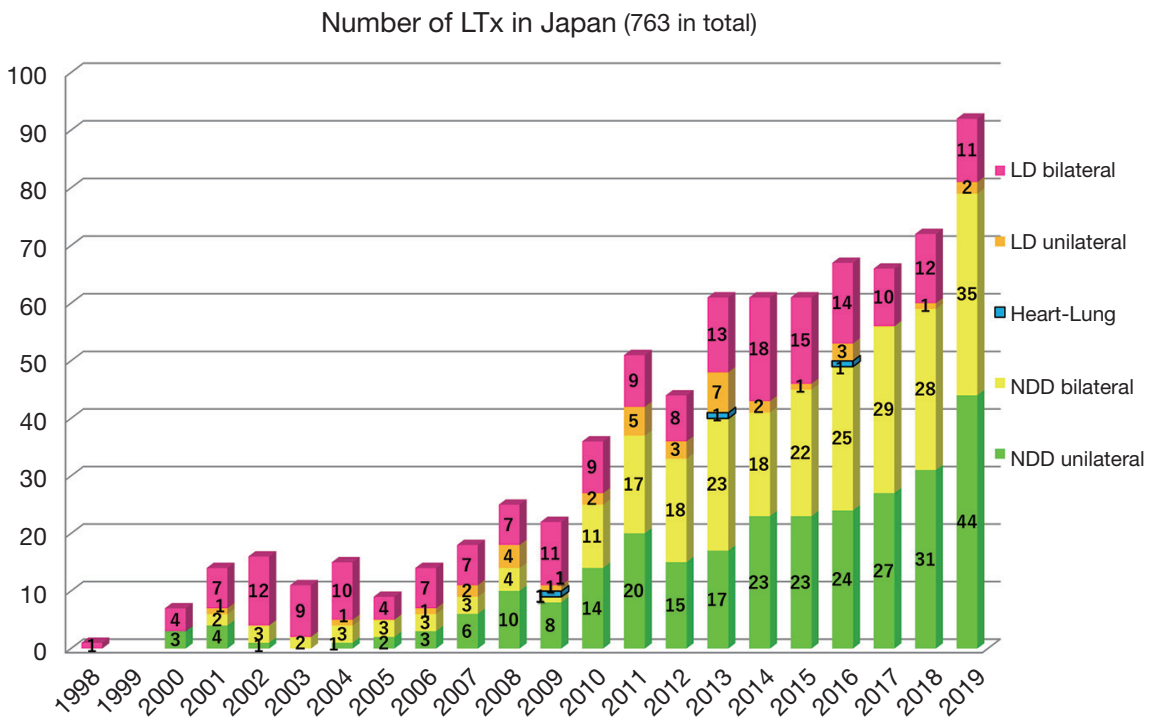

Figure 1 Number of LTx procedures in Japan. The figure shows the number of bilateral LD LTx, unilateral LD LTx, heart-lung transplantation, bilateral NDD LTx, and unilateral NDD LTx procedures performed every year. This figure was reproduced from reference (1) with permission from the Japanese Society of Lung and Heart-lung Transplantation. LTx, lung transplantation; LD, living donor; NDD, neurologically dead donor.

procedures performed. LTx has increased since then (1) (Figure 1). However, the number of registered patients awaiting LTx has also been increasing. Therefore, the shortage of donors remains problematic. This is why livingdonor LTx continues to be performed. The average waiting time for LTx is 2 years 5 months in Japan.

\section{Registration process}

An age limitation is enforced for recipients of LTx in Japan. Patients must be $<60$ years of age to be registered on the waiting list for unilateral LTx and $<55$ years of age for bilateral LTx. Patients are registered on the list at the Japan Organ Transplant Network, which is the central organization in Japan, once the assessment and document process has been completed. As of 2020, nine hospitals in Japan are allowed to perform LTx. All LTx programs are mainly run by thoracic surgeons in their own way. The transplant pulmonologists are scarce in Japan. Each patient is registered through one of those nine hospitals.

To be eligible for a lung transplant from NDD, the patient must meet the following requirements: (I) The patient must have a poor prognosis. (II) The patient must have no other life-threatening systemic disease. (III) The patient must have demonstrated absolute compliance with medications and medical recommendations, and have good rehabilitation potential. (IV) The patient must demonstrate emotional stability. (V) The patient must have a supportive person or supportive social system.

After the assessment at each hospital, a second assessment is performed in the Japan central assessment meeting, which mainly involves respirologists. Each patient belongs to one of the nine LTx hospitals where he or she will undergo LTx in the future. However, a waiting list is common among the hospitals. For example, the first patient on the list belongs to The University of Tokyo Hospital. The second and third patients on the list belong to Kyoto University Hospital. The organ offer is sent to the thoracic surgeon according to the patient's turn. There is no priority system based on severity or urgency. There is sometimes a situation of very early referral and registration for LTx in order to gain "waiting time". Sometimes patients are too stable to have LTx when they actually receive an organ offer. Once patients are registered for LTx, they must wait for their turn. The information used for allocation includes the patient's blood type, lung size match (within $\pm 30 \%$, which is calculated with the predicted donor vital capacity and predicted recipient vital capacity), negative crossmatch (we use the complement-dependent method as of 2020), and waiting time. Only children have priority. Donors aged $<18$ years are first offered to patients aged $<18$ years. Although the number of NDDs has been gradually increasing, the 



Figure 2 Numbers of patients who underwent LTx and their original lung diseases. (A) Recipients of bilateral LTx from a neurologically dead donor. (B) Recipients of unilateral LTx from a neurologically dead donor. (C) Recipients of bilateral and unilateral LTx from a living donor. This figure was reproduced from reference (1) with permission from the Japanese Society of Lung and Heart-lung Transplantation. NDD, neurologically dead donor; LTx, lung transplantation; PAH, pulmonary arterial hypertension; IIP, idiopathic interstitial pneumonia; IP, interstitial pneumonia; post-HSCT lung disease, post-hematopoietic stem cell transplant lung disease; LAM, lymphangioleiomyomatosis; CF, cystic fibrosis; COPD, chronic obstructive pulmonary disease; OB, obliterative bronchiolitis.

number of patients who die while awaiting LTx is not small because there is no priority allocation based on severity.

Because of the shortage of donors, we basically register patients for unilateral LTx to maximize the number of people who can be saved from one donor only if the patients do not have pulmonary arterial hypertension $(\mathrm{PAH})$ and chronic pulmonary infection. Therefore, the most common type of registration is unilateral LTx as the first option and bilateral LTx as the second option.

Post-op follow-up care are also mainly done by thoracic surgeons at the LTx centers. If the patient lives far away from the center, the patient is referred to a respirologist or a thoracic surgeon near the patient home.

\section{Original diagnoses of recipients}

A total of 250 patients underwent bilateral LTx from NDDs from 1998 to 2019 (1) (Figure 2A). The most common indication for bilateral LTx was idiopathic PAH, followed by interstitial pneumonia (IP), including idiopathic IP and IP of other causes. PAH is a definite indication for bilateral LTx to secure an adequate pulmonary vascular bed. Several medications are available for patients with $\mathrm{PAH}$, such as continuous intravenous epoprostenol injection. These medications allow patients with PAH to wait for an NDD in spite of the long waiting time. In total, 276 unilateral LTx procedures from NDDs have been performed, mainly for IP and lymphangioleiomyomatosis (Figure 2B). Because we limit the age of the recipient, patients with chronic obstructive pulmonary disease/emphysema do not comprise the majority of LTx recipients, unlike in the international statistics. The number of unilateral LTx procedures is greater than the number of bilateral LTx procedures.

\section{Problematic long waiting time}

A certain proportion of patients die while awaiting LTx because of the long waiting time. This is a major problem. In addition, several disease-specific issues are caused by the long waiting time.

\section{$P A H$}

While awaiting LTx, patients' dosages of medications 
(especially continuous intravenous vasodilators) are usually increased. This increases the risk of bleeding during LTx and makes the surgery more difficult. Hemostasis often takes a long time to achieve during LTx. In addition, right heart failure is common at the time of LTx. The right ventricle is enlarged, and the left ventricle has acclimated to the low-volume load. After LTx, the left ventricle suddenly receives a much higher-volume return from the lungs. During postoperative management, we must be extremely careful to prevent sudden left heart failure. In addition to intraoperative venoarterial extracorporeal membrane oxygenation (ECMO), postoperative venoarterial ECMO is often used to avoid sudden heart failure.

\section{IP}

At the time of registration, right-side cardiac catheterization is always performed to check for the presence of secondary PAH. Only patients without PAH are registered for unilateral LTx. However, during the long waiting time, the pulmonary vascular resistance and pulmonary artery pressure increase with progression of the disease in some patients. This often occurs in patients with IP. The respirologists who refer the patients to the thoracic surgeons at LTx hospitals are usually responsible for the patients' medical treatment during the waiting time. Some of them regularly perform cardiac ultrasound examinations, but it is sometimes difficult to accurately diagnose PAH based on ultrasound. Unilateral LTx should be avoided in patients with secondary PAH. If patients develop PAH, the surgeon must consider switching from unilateral to bilateral LTx. When information regarding the possible development of $\mathrm{PAH}$ is received from the respirologist, reassessment with cardiac catheterization should be planned. However, we sometimes first observe PAH in patients with IP on the monitor from the Swan-Ganz catheter inserted at the time of unilateral LTx. Unfortunately, even in the situation, we basically do not have any other option except continuing the planned unilateral LTx for the patient.

\section{How we challenge the shortage}

\section{Medical consultants for donor management}

We utilize a medical consultant system in which medical consultants give suggestions to the intensivists who care for possible donors. This system helps to improve the graft condition and increase the number of actual donors (2).
Once the Japan Organ Transplant Network receives an offer from a donor hospital and confirms the donor's neurologically dead status, they send one of the thoracic surgeons who belong to one of the nine LTx hospitals as a medical consultant. The consultant checks all necessary information, including the chest radiographs and computed tomography images, laboratory data, culture status, and fluid balance. In many cases, the possible donor has already been intubated for a few or several weeks when the organ offer is sent to the network. The donor is often at risk of ventilator-associated pneumonia. The consultant performs bronchoscopy, and if there is any concern about pneumonia, the consultant suggests starting antibiotic therapy or switching the antibiotic to one with a broader spectrum. The interval from the consultant's intervention and actual lung procurement is usually about 2 days. Thus, the antibiotics may start working before procurement. In some cases, the consultant's suggestions are quite effective. The utility ratio of the lungs of brain-dead donors in Japan is indeed over $60 \%$ (3) and it is much higher than that reported in the USA.

\section{Aggressive use of marginal donors}

We aggressively use marginal donors (4) such as older donors, smokers, suicidal hanging donors, donors who have contralateral pneumonia, and donors with a long intubation time. There are no standard criteria with which to accept a marginal donor. We carefully assess each donor's information. Many donors are around 60 years of age and have a smoking history. The chest radiographs are not always clear. By carefully assessing the serial laboratory data, chest radiographs, and fluid in-out balance on a daily basis, we are able to determine whether opacities in the lung field on chest radiographs represent pleural fluid, atelectasis, or actual pneumonia. If the donor has pneumonia, we assess whether the pneumonia is improving or worsening. If it is improving, we are able to treat the pneumonia with antibiotics and we therefore consider using the donor. Among several parameters, $\mathrm{PaO}_{2} / \mathrm{FiO}_{2}$ ratio of $>300$ seems to be particularly important, as other research groups have mentioned (5); however, other assessment parameters and statistics are also needed.

Another way to utilize marginal donors is to remove the diseased parts of lungs at the back table (6). For example, the heavy edematous right lower lobe was resected at the back table in one case because the lobe appeared to be unrecoverable. Lobectomy for a graft may also be an option 
to protect other healthy lobes as long as the size of the lungs remains adequate after the lobectomy.

\section{Long-term preoperative ECMO support}

Here in Tokyo, we experienced two cases of bilateral LTx after $>3$ months of ECMO support. One case has already been reported in Japanese (7). The case involved a patient who underwent preoperative venovenous ECMO for bronchiolitis obliterans following allogeneic bone marrow transplantation. The ECMO support was discontinued in the operation room at the time of LTx. The other case involved a patient who underwent preoperative venoarterial ECMO for idiopathic IP and has not yet been officially reported. Both patients were preoperatively managed in the ECMO center at the hospital close to The University of Tokyo Hospital, and they were then transferred to us when they had donor calls. Careful professional management of patients undergoing ECMO at the special center is required in these challenging situations. Both patients underwent bilateral LTx. At the time of this writing (1 year after LTx), they were doing well at home without oxygen therapy.

In both of these cases, the transplant surgeons and the intensivists at the ECMO center had a thorough discussion before the patients were placed on ECMO. The main discussion point was how close the patient was to LTx and if the patient could continue rehabilitation on ECMO to maintain their general condition. The information that is required to determine how soon the patient will undergo LTx includes how much time has passed since the registration, the patient's blood type, and the patient's body size. Lung allocation is based on blood type and body size; therefore, if the patient is extremely small relative to the population and only a few months have passed since registration, the patient is not likely to undergo LTx within several months. The patient is not placed on ECMO in such circumstances.

The use of ECMO in support of patients awaiting lung transplant might not affect the lung transplant numbers, but can improve the wait-list mortality.

\section{Living-donor LTX}

Living-donor LTx is an ultimate option to rescue a recipient whose condition is serious and who cannot wait 2 to 3 years for a cadaveric donor to become available. There is no definite indication for living-donor LTx. Basically, in Japan, a living lung donor should be a relative or a legal partner aged $<60$ years. Therefore, living-donor LTx is a feasible option only for patients who are fortunate to have such a living donor. A typical case is a pediatric recipient whose donor is one or both of the child's parents. A child can also serve as the donor to his or her recipient parent. A sibling, wife, or husband can also be a donor. The relationship between the donor and recipient should be confirmed with legal documentation before planning living-donor LTx.

In total, 234 cases of living-donor LTx were performed from 1998 to 2019 in Japan (Figure 2C). The recipients' diagnoses were post-hematopoietic stem cell transplant lung disease, idiopathic IP, PAH, and others. As stated above, the combination of a parent donor and child recipient is the most common; therefore, the most common reason for living-donor LTx is post-hematopoietic stem cell transplant lung disease.

Living-donor LTx involves the performance of lobar transplantation. The graft is usually the right lower lobe or left lower lobe. If the recipient requires bilateral LTx, two living donors are needed: one donor for the right side and another donor for the left side. The total graft volume must be $>45 \%$ of the recipient's predicted forced vital capacity (8). Size matching between the donor and recipient is important. The graft lung volume from a living donor is smaller than that from a cadaveric donor. Native upper lobe-sparing living-donor lobar LTx was recently developed to overcome a small-for-size graft in Kyoto (9). Another useful option for overcoming a small-for-size graft, which was also developed in Kyoto, is inverted right to left livingdonor LTx (10).

There are other differences between living-donor LTx and cadaveric LTx. In living-donor LTx, the grafts are usually excellent in quality and the ischemic time is minimal because we can start harvesting the graft when the recipient is ready. However, there is always the ethical concern about performing an invasive surgery on healthy people. The percentage of intra- or perioperative complications of living-donors has not been well documented. Reported complications of lung donors are the necessity of a right middle lobe sacrifice, pericarditis, and accumulation of pleural effusion which needed chest tube drainage. There has been no reported perioperative mortality of a lung living-donor.

\section{Outcomes}

Although we aggressively use marginal donors, the LTx outcomes in Japan are comparable with the international 
Outcomes (1998-2019)



Figure 3 Cumulative survival rate after lung transplantation. Each survival rate was calculated using the Kaplan-Meier method, which incorporates information from all transplant recipients for whom any follow-up has been provided. LTx, lung transplantation; NDD, neurologically dead donor, LD, living donor. This figure was reproduced from reference (1) with permission from the Japanese Society of Lung and Heart-lung Transplantation.

outcomes (11) (Figure 3). The 5-year survival rate calculated using the Kaplan-Meier method was $74.4 \%$ in the NDD bilateral LTx group, $68.4 \%$ in the NDD unilateral LTx group, $73.8 \%$ in the living-donor bilateral LTx group, and $73.0 \%$ in the living-donor unilateral LTx group. Although the quality of the living donor lung should be better than most of brain-dead donor lungs, the long-term survival is comparable between the living-donor LTx and NDD LTx. Size-mismatch in living-donor LTx might lower the survival rate of livingdonor LTx. The leading causes of death of recipients after LTx are infection and chronic lung allograft dysfunction.

\section{Conclusions}

The shortage of NDDs is problematic in Japan. However, we continue to challenge the shortage by using marginal donors, a medical consultant system, living-donor LTx, and long-term preoperative ECMO support. Despite this challenging situation, our outcomes are comparable with the international outcomes. With these experiences and an increase in the number of NDDs, Japanese LTx can become a more successful program.

\section{Acknowledgments}

We thank Angela Morben, DVM, ELS, from Edanz Group (https://en-author-services.edanzgroup.com/ac), for editing a draft of this manuscript.

Funding: None.

\section{Footnote}

Provenance and Peer Review: This article was commissioned by the Guest Editors (Jing Yu Chen and Michael Hsin) for the series "Highlights of the First International Symposium on Lung transplantation, Wuxi, China, 2019" published in Current Challenges in Thoracic Surgery. The article has undergone external peer review.

Peer Review File: Available at https://ccts.amegroups.com/ article/view/10.21037/ccts-20-143/prf

Conflicts of Interest: Both authors have completed the ICMJE uniform disclosure form (available at https://ccts.amegroups. com/article/view/10.21037/ccts-20-143/coif). The series "Highlights of the First International Symposium on Lung transplantation, Wuxi, China, 2019" was commissioned by the editorial office without any funding or sponsorship. The authors have no other conflicts of interest to declare.

Ethical Statement: The authors are accountable for all aspects of the work in ensuring that questions related 
to the accuracy or integrity of any part of the work are appropriately investigated and resolved.

Open Access Statement: This is an Open Access article distributed in accordance with the Creative Commons Attribution-NonCommercial-NoDerivs 4.0 International License (CC BY-NC-ND 4.0), which permits the noncommercial replication and distribution of the article with the strict proviso that no changes or edits are made and the original work is properly cited (including links to both the formal publication through the relevant DOI and the license). See: https://creativecommons.org/licenses/by-nc-nd/4.0/.

\section{References}

1. Registry report from the Japanese Society of Lung and Heart-lung Transplantation. Available online: http:// www2.idac.tohoku.ac.jp/dep/surg/shinpai/pg185.html

2. Hoshikawa Y, Okada Y, Ashikari J, et al. Medical consultant system for improving lung transplantation opportunities and outcomes in Japan. Transplant Proc 2015;47:746-50.

3. Date H. Current status and problems of lung transplantation in Japan. J Thorac Dis 2016;8:S631-6.

4. Botha P, Trivedi D, Weir CJ, et al. Extended donor criteria in lung transplantation: impact on organ allocation. J Thorac Cardiovasc Surg 2006;131:1154-60.

doi: $10.21037 /$ ccts-20-143

Cite this article as: Konoeda C, Sato M. Current situation of lung transplantation in Japan. Curr Chall Thorac Surg 2022;4:6.
5. De Wolf J, Renard R, Lehouerou T, et al. Hanging donor lungs give good short-, mid- and long-term results in lung transplantation. Clin Transplant 2020;34:e13758.

6. Kayawake H, Chen-Yoshikawa TF, Aoyama A, et al. Surgical management of bronchial stumps in lobar lung transplantation. J Thorac Cardiovasc Surg 2018;156:451-60.

7. Sato S, Tanaka E, Tachibana T, et al. Successful lung transplantation after long-term ventilator and extracorporeal membrane oxygenation support in a patient with severe bronchiolitis obliterans following allogeneic bone marrow transplantation. Rinsho Ketsueki 2019;60:920-3.

8. Date H. Update on living-donor lobar lung transplantation. Curr Opin Organ Transplant 2011;16:453-7.

9. Takahagi A, Chen-Yoshikawa TF, Saito M, et al. Native upper lobe-sparing living-donor lobar lung transplantation maximizes respiratory function of the donor graft. J Heart Lung Transplant 2019;38:66-72.

10. Chen-Yoshikawa TF, Tanaka S, Yamada Y, et al. Intermediate outcomes of right-to-left inverted livingdonor lobar lung transplantation. Eur J Cardiothorac Surg 2019;56:1046-53.

11. Registry data from the International Society for Heart and Lung Transplantation. Available online: https:// ishltregistries.org/registries/slides.asp 